\title{
Climate Change: Impact on Viral Diseases
}

\author{
Evelyne Schvoerer ${ }^{*}, 1$, Jean-Pierre Massue ${ }^{2}$, Jean-Pierre Gut ${ }^{1}$ and Françoise Stoll-Keller ${ }^{1}$ \\ ${ }^{I}$ Virology Institute, University Hospital of Strasbourg, 3 Koeberlé Street, 67000 Strasbourg, France \\ ${ }^{2}$ European Expert, Previously Working in the Secretariat of Major Hazards Agreement, European Council, Strasbourg, \\ France
}

\begin{abstract}
Gas emission by humans will change climate, warming by $1.4-5.8^{\circ} \mathrm{C}$ as predicted at the end of the current century. Climate oscillations between warm and cold phases (El Niño) add complexity in the field. The effects on health could be thermal stress, extreme weather events, and subsequently emerging infectious diseases. Consequences on food yields, social, demographic and economic imbalances, could also favour contagious diseases.

Increasing vector-borne infections could represent a major health concern. Additionally, numerous floods and massive movements of people could facilitate the transmission of water-borne infections. Moreover, decrease in food supply could disorganise populations with crowding and concomitant spreading of transmissible infectious pathogens such as viruses.
\end{abstract}

This short review aims to present the potential viral impact on human health in case of climate change, i.e. increased arboviruses, "tropical" viruses, and viral infections related to overcrowding in poor healthy context.

\section{INTRODUCTION}

There is a consensus that gas emission generated by humans will change climate, recently warming with an increase of $1.4-5.8^{\circ} \mathrm{C}$ predicted for 2100 . The main effects on health could be thermal stress, extreme weather events, and infectious diseases changing in their location or frequency. A more global approach has to take into account difficulties in food yields, social, demographic and economic imbalances, which could favour emerging infectious pathogens. The main known or probable health hazards of climate change could be summarized as following [1-3]:

- $\quad$ First, very hot days and aero-allergen production would provoke more severe diseases and more deaths. Everybody reminds, as an example, the excess in mortality ratio observed in France during the summer heat 2003. 56,000 deaths were reported in August 2003 , corresponding to 15,000 additional victims as compared to expected mortality $[4,5]$.

- $\quad$ Second, a crucial concern would emerge with increasing vector-borne infections, favoured by a large distribution of insects dispersing infectious agents. Fighting against serious viral related diseases or malaria would then represent a high health priority [1].

- $\quad$ Third, flooding, the most frequent natural water disaster representing $43 \%$ of the disasters reported between 1992 and 2001, has killed 100,000 people worldwide during this period [1]. In the future, numerous predicted floods, and, as a consequence, sudden and massive movements of people could facilitate the transmission of contagious diseases. Water-borne

*Address correspondence to this author at the Virology Institute, University Hospital of Strasbourg, 3 Koeberlé Street, 67000 Strasbourg, France; Tel: (33) 390243696; Fax: (33) 390243750;

E-mail: Evelyne.Schvoerer@chru-strasbourg.fr infections such as enteric viruses-linked pathology or cholera could threaten large parts of populations.

- Moreover, decrease in crop yields and fisheries, or sea-level rise could lead to messy displacements and to concentration of populations.

- In a convergent manner, climate oscillations between extreme warm and cold phases (El Niño), could modify the dynamics of viruses transmission, as it will be further developed [6].

The aim of this short review is to summarise the impact of climate change on viral infections. We will first simply define viruses and their circulation. The presentation will then be divided in two parts: (i) direct impact of climate change in the increase of viral infections, mainly mosquitotransmitted viruses; (ii) indirect impact of climate events, favouring movements of populations, overcrowding, and the emergence of viral diseases facilitated by contacts between humans, humans and animals, humans and spoiled water (Table 1).

Table 1. Climate Change and Health Impact, Adapted from [1]

\begin{tabular}{|c|c|}
\hline Change & Adverse Effects \\
\hline More very hot days, allergens & More deaths \\
\hline $\begin{array}{l}\text { Warming temperatures/ } \\
\text { rainfall/ conditions favouring } \\
\text { insects proliferation }\end{array}$ & $\begin{array}{l}\text { Vector-borne infections: } \\
\text { Arboviruses, malaria }\end{array}$ \\
\hline Floods & $\begin{array}{c}\text { Movement of people/crowding } \rightarrow \\
\text { - more infectious diseases } \\
\text { - water-borne infection } \\
\text { enteric viruses, cholera }\end{array}$ \\
\hline $\begin{array}{c}\text { Decrease in crop yields, } \\
\text { in fisheries } \\
\text { Sea-level rise }\end{array}$ & $\begin{array}{c}\text { Movement of people/crowding } \rightarrow \\
\text { viral gastroenteritis } \\
\text { viral respiratory epidemics }\end{array}$ \\
\hline
\end{tabular}

2008 Bentham Open 


\section{WHAT IS A VIRUS?}

It is an infectious agent, defined by a simple structure made of two or three elements:

- the genetic information (viral genome) coding for viral enzymes and proteins, corresponding to DNA or RNA;

- the viral capsid, all around the genome, a protein structure protecting DNA or RNA;

- the viral envelope, containing lipids and proteins, which is not constantly present.

A virus needs living cells to proliferate. On the contrary, bacteria are able to proliferate on inert lifeless medium containing sugar and amino acids. The presence of sensitive cells is necessary to allow free viruses or viruses coming from infected cells to replicate: new viruses in newly infected cells are then produced from parental viruses using and diverting cellular tools. Viruses cannot proliferate in the outside environment, if they are not in sensitive and living hosts. Thus, multiplication of the viruses in host cells will provoke cellular damage and symptoms observed in infected humans or animals.

Elsewhere, a virus with capsid but without any envelope will potentially resist in the outside environment, for several weeks or months, preserving its entire ability to re-infect and proliferate in naïve humans or animals. Viruses provoking gastroenteritis, usually non enveloped and resistant in water environment, have to be mentioned in this context.

Oppositely, enveloped viruses are usually vulnerable in outside environment, rather transmitted by direct contact between infected individuals (humans or animals) and exposed naive, i.e. non immunized people. As an example, influenza virus can be mentioned, of which the transmission can be favoured by close contacts between individuals and also by both cold and dry conditions [7]. At last, enveloped viruses can also be transmitted by intermediate insects such as mosquitoes.

\section{DIRECT IMPACT OF CLIMATE CHANGE ON VIRAL DISEASES TRANSMISSION IN HUMANS}

Higher temperatures at earth's surface will provoke an increase in global average rainfall, although some mid latitude will become drier. Rainfall can promote transmission of vector-borne pathologies by creating ground pools and other breeding sites for insects. Moreover, drought may cause flowing water to stagnate; drought may also stimulate people to store water in cisterns, and containers that also serve as breeding sites for mosquitoes. Elsewhere, one can assume that massive clearance of the forests exposed to warming climates could allow contacts between non immune humans with dangerous viral infectious cycles and their corresponding reservoirs from the forests $[3,8]$.

As a global consequence, the spread of viruses restricted to tropical areas until now could occur in the future. It is commonly admitted by experts in vectors cycles that mosquito-related diseases, especially arboviruses in virology field, able to cause very serious haemorrhagic fevers, could thus emerge in case of climate warming.
Thus, the spread of "exotic" viruses could be observed in Europe and North America. Emerging arboviruses (Arthropod-Borne viruses) such as Dengue virus, Chikungunya virus, West Nile virus, Tick-Borne Encephalitis virus, Rift Valley Fever virus, Japanese encephalitis virus, CrimeanCongo haemorrhagic fever virus could be reported and viruses from the forests could threaten humans, such as Yellow Fever Virus [9-13].

\section{1.a. Arboviruses: Dengue Virus}

This Flavivirus (types 1, 2, 3, 4), transmitted by Aedes aegypti and Aedes albopictus (Fig. 1), is observed in the equatorial areas of America, Africa and Asia with increasing reports of epidemics in the recent years. The corresponding health concern is estimated as 50-100 000000 cases a year, with 250,000 haemorrhagic forms $[9,10]$.

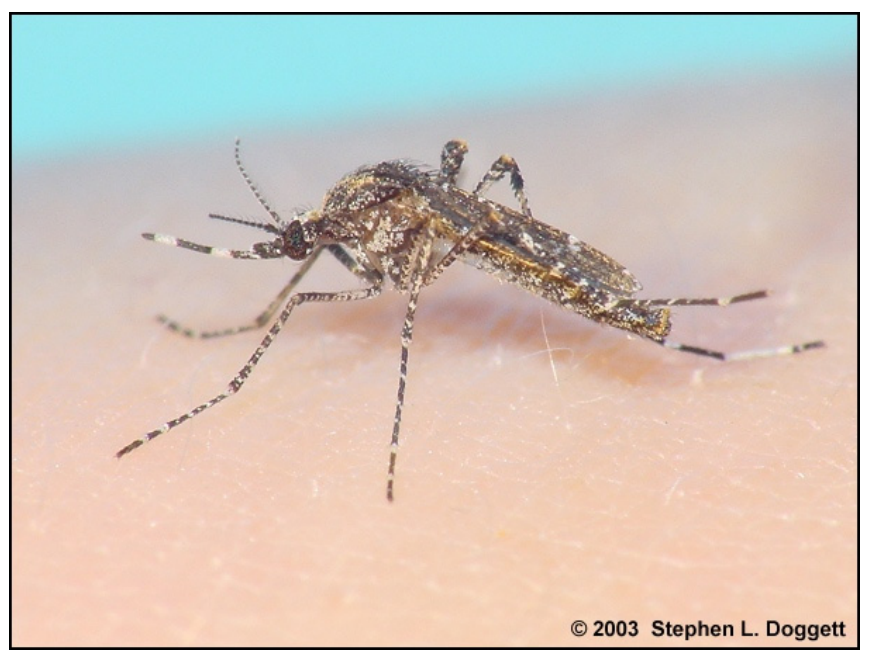

Fig. (1). Mosquito, Aedes.

Dengue virus can provoke fever, pains, rash and, in about $10 \%$ of the cases, serious haemorrhagic syndromes, especially in Asia and in children. The severity of secondary infections has to be underlined. Thus, reinfection by a viral type different from the primary infection could be more serious, maybe by production of "facilitating" antibodies, which are not protective but deleterious. In the absence of any effective vaccine, the prevention consists in mosquito control.

\section{1.b. Arboviruses: Yellow Fever}

This Flavivirus is principally transmitted by Aedes aegypti in forest and urban locations. It is largely observed in the equatorial areas of Africa and America. The estimation of the related public health concern is approximately 200,000 cases a year, with 30,000 fatal cases. The severe cases consist of asthenia, alterations in kidney, liver, and heart function with diffuse haemorrhagic signs.

The prevention corresponds to the control of mosquitoes. Moreover, the use of a very effective vaccine, obligatory for foreign travellers in endemic countries would be crucial to be developed in case of increasing incidence of the disease.

Elsewhere, climate warming could alter forests and favour contact between non immune humans and certain forest transmission cycles. Indeed, highly dangerous viruses, leav- 
ing the forest, could then provoke epidemics in humans. This concern could involve Yellow Fever virus.

\section{1.c. Arboviruses: West Nile Virus}

West Nile Virus (WNV), another Flavivirus, is transmitted to birds and transferred by Culex mosquitoes. Humans and horses are incidental hosts for the viruses. WNV fever appears mostly at the end of the summer, able to provoke fatal human meningitidis or encephalitis in elderly patients. WNV is endemic in Africa, south-western Asia, eastern and southern Europe and in the Mediterranean basin. It was also frequently detected in North, Central and South America and in the Caribbean. Paz and Albersheim [13] analyzed the correlation between weather conditions (especially air temperature) and Culex pipiens mosquito abundance, and WNV fever frequency in humans between 2001 and 2005 in Israel. Israel is a major stopover for huge flocks of migrating birds, the reservoir of WNV. In 2000, a large outbreak of 429 cases (35 deaths) occurred in Israel with very hot previous summer and long heat waves, comparably to the outbreaks previously reported in Romania (1996) and in New York city (1999). There was a recent tendency for temperature increase in the hot season in Israel. These positive anomalies of the temperature appear to have increased the quantity of mosquitoes and the disease in humans. Most of the WNV fevers occurred in the Tel Aviv metropolis, where the risk is very intense due to the combination of high temperatures, a high level of air humidity, and a high population density. In the context of future uncertainty on climate change, WNV has to be considered as an important health concern.

\section{1.d. Arboviruses: Tick-Borne Encephalitis Virus}

Tick-borne encephalitis virus (TBE) is transmitted by Ixodes ticks in an area from western Europe to the eastern cost of Japan. TBE virus causes acute meningoencephalitis, more or less severe. Climate change is partly responsible for increased incidence of the disease in Europe. TBE virus was shown to circulate at increasing altitudes in Czech Republic; in Sweden, a northward expansion of I. Ricinus is seen, and mild winters and early springs are associated with more frequent disease (see [14] for review).

\section{1.e. Other Viruses}

The 1993 outbreak of hantavirus pulmonary syndrome (Sin Nombre virus) in the United States deserves to be mentioned. It followed a dramatic increase in precipitation associated with the 1992 and 1993 El Niño phenomenon. This resulted in an abundance of rodent food resources (vegetation and insects) and a 20 -fold rodent population increase, favouring viral transmission from rodent to human [15].

The difficulties in organizing virological diagnosis of the above mentioned diseases, in taking care of the patients and avoiding secondary transmission could be very serious, in the absence of strong health networks. Moreover, weak healthy structures in Africa could make prevention difficult in case of modifications in forest areas and subsequent diffusion of infectious agents. Treatment of the corresponding infections are difficult or inefficient. The prevention is crucial, corresponding to the destruction of mosquitoes, to the control of contacts between ill patients and healthy people, between non immune humans and the forest infectious cycles.

\section{INDIRECT IMPACT OF CLIMATE CHANGE ON THE DISTRIBUTION OF VIRAL DISEASES}

A major effect could be observed in climate conditions disturbing the organisation of social and economical features in the populations. Thus, displacing populations and overcrowding could facilitate contacts between humans, between humans and animals and between humans and spoiled waters, favouring infections related to enteric or respiratory viruses [16]. These pathogens, thereby encountering good conditions for spreading, could develop as big epidemics, possibly all over the world for diseases such as Flu.

\section{2.a. Water-Borne Diseases}

Water-borne diseases are important risks in case of climate change and subsequently in case of floods and extreme climate events. Viral gastroenteritis (rotavirus, calici/norovirus) could burst in these conditions. Caliciviruses are responsible for more than $90 \%$ of gastroenteritis outbreaks and could easily circulate worldwide [17]. Hepatitis A virus can provoke acute hepatitis and possible fulminant cases of hepatitis in 40 year-old adults from non endemic areas. Hepatitis E virus can also be responsible for fatal hepatitis in pregnant women. The protection of water networks against enteric pathogens would thus be crucial.

\section{2.b. Respiratory Diseases}

Influenzae (Flu) viruses have to be included into possible nuisances of climate change and consequent massive movements of people. This potential severe respiratory illness can indeed burst in favouring conditions. In 1918, "Spanish" flu developed because of insufficient immunity in individuals, closely joined humans and highly pathogenic Flu viruses from birds (virus $\mathrm{A}(\mathrm{H} 1 \mathrm{~N} 1)$ ). Two other pandemics were later observed, in 1957 (virus A(H2N2)) and in 1968 (virus $\mathrm{A}(\mathrm{H} 3 \mathrm{~N} 2)$. These two latter viruses were the result of combinations between human and avian viral strains in China.

Here a particular phenomenon, making more complex the prediction of health impact in case of climate change, deserves to be mentioned. The El Niño Southern Oscillation (ENSO) undergoes cycles between extreme warm phases and reverse cold phases. The subsequent changes in local conditions may affect respiratory virus survival and/or human indoor crowding. Cold ENSO phases have been associated with possible promotion of larger and more severe influenza epidemics [6].

Another factor has to be taken into account: the inactivation of viruses in the environment by solar UV radiation plays a role in the seasonal occurrence of influenza pandemics [18], which could be modified in case of climate change. Moreover, a recent study on influenza virus deserves to be mentioned here. Using the guinea pigs as a model, Lowen et al. [7] showed that aerosol spread of influenza virus is dependant on both relative humidity $(\mathrm{RH})$ and temperature. By demonstrating that both cold and dry conditions favour transmission, these authors made more clear the predominant wintertime spread of Flu. They observed on their animal model that transmission was highly efficient at low RH of $20-35 \%$ and was inversely correlated with temperature, i.e. more efficient at $5^{\circ} \mathrm{C}$ than at $20^{\circ} \mathrm{C}$. They also reported that viral shedding was increased in animals at $5^{\circ} \mathrm{C}$, favouring increased transmission under cold conditions. Thus, complex 
modifications in climate characteristics could change the epidemiology of the disease.

As another example, Severe Acute Respiratory Syndrome (SARS) could re-emerge. This coronavirus from Asia provoked severe acute pneumonia in 2003. Close contacts between humans and Chinese animals (wild civets sold in rural markets, bats) could be the source of the epidemics. In case of climate disasters, favoured by globalization with worldwide trip facilities, the diffusion of this pathogenic agent, which quickly travelled from Guangzhong to Hong Kong and to Toronto in the past, could be recurrent [3].

\section{PERSPECTIVES}

As a conclusion, we have to be ready, in case of climate change, to take into account the potential increase in mosquito-borne viral infections and in diseases which are facilitated by close contacts between humans, humans and animals, humans and spoiled water.

Experts in climate changes, which are complex and increasing, are crucially needed. Healthy networks, able to survey the distribution and circulation of emerging infectious pathogens are essential.

The prevention of serious consequences of climate change on infectious diseases and human health will consist in first, the control of mosquito spreading, second, the control of people displacements; third, water quality will be crucial to be preserved in case of disruption of social organisations provoked by climate events. At last, production of vaccines and specific treatments, if developed by scientists, should be drastically increased by the pharmaceutical industry in case of epidemics.

\section{REFERENCES}

[1] McMichael AJ, Woodruff RE, Hales S. Climate change and human health: present and future risks. Lancet 2006; 367: 859-69.
[2] Reiter P. Climate change and mosquito-borne disease. Environ Health Perspect 2001; 109: 141-61.

[3] Weiss RA, McMichael AJ. Social and environmental risk factors in the emergence of infectious diseases. Nat Med 2004; 10: S70-6.

[4] Valleron A, Boumendil A. Epidemiology and heat waves: analysis of the 2003 episode in France. C R Biol 2004; 327: 1125-41.

[5] Schär C, Vidale PL, Lüthi D, et al., The role of increasing temperature variability in European summer heatwaves. Nature 2004; 427: 332-6.

[6] Viboud C, Pakdaman K, Boëlle PY, et al. Association of influenza epidemics with global climate variability. Eur J Epidemiol 2004; 19: 1055-9.

[7] Lowen AC, Mubareka S, Steel J. Palese P. Influenza virus transmission is dependent on relative humidity and temperature. PLoS Pathog 2007; 3: 1470-6.

[8] Isaäcson M. Viral hemorrhagic fever hazards for travelers in Africa. Clin Infect Dis 2001; 33: 1707-12.

[9] Geisbert TW, Jahrling PB. Exotic emerging viral diseases: progress and challenges. Nat Med 2004; 10: S110-21.

[10] Mackenzie JS, Gubler DJ, Petersen LR. Emerging flaviviruses: The spread and resurgence of Japanese encephalitis, West Nile and dengue viruses. Nat Med 2004; 10: S98-109.

[11] Flahault A. Emerging infectious diseases: the example of the Indian Ocean chikungunya outbreak (2005-2006). Bull Acad Natl Med 2007; 191: 113-24; discussion 125-8.

[12] Gould EA, Higgs S, Buckley A, Gritsun TS. Potential arbovirus emergence and implications for the United Kingdom. Emerg Infect Dis 2006 ; 12 : $549-55$.

[13] Paz S, Albersheim I. Influence of warming tendency on Culex Pipiens population abundance and on the probability of West Nile Fever outbreaks (Israeli Case Study: 2001-2005) EcoHealth 2008; 5: 40-8.

[14] lindquist L, Vapalahti O. Tick-borne encephalitis. Lancet 2008; 371: 1861-71.

[15] Engelthaler DM, Mosley DG, Cheek JE, et al., Climatic and environmental patterns associated with hantavirus pulmonary syndrome, Four Corners region, United States. Emerg Infect Dis 1999; 5: 87-94.

[16] Choi K, Christakos G, Wilson ML. El Niño effects on influenza mortality risks in the state of California. Public Health 2006; 120: 505-16.

[17] Koopmans M, Duizer E. Foodborne viruses: An emerging problem Int J Food Microbiol 2004; 90: 23-41.

[18] Sagripanti J, Lytle CD. Inactivation of influenza virus by solar radiation. Photochem Photobiol 83: 1278-82. 